\title{
Design of Online Courses Based on Mobile Phone Learning
}

\author{
Guanqun Liu \\ Department of Computer Science, Hunan Radio \&TV \\ University, Changsha, China \\ Email: liuguanqun05@yeah.net
}

\author{
Qiufen Yang \\ Department of Computer Science, Hunan Radio \&TV \\ University, Changsha, China \\ Email: yqf5569@sohu.com
}

\author{
Rong Fan \\ Department of Computer Science, Hunan Radio \&TV University, Changsha, 410004, China \\ Email:fareu@126.com
}

\begin{abstract}
In recent years, with the deveopment of mobile communications, the new learning mode - mobile learning gains popularity gradually as one important teaching carrier in modern remote education. Besides, it has attracted more and more educators engaging in various areas. When designing the online course of "Basis of Muti-media Technology", the course group has developed the online learning course suitabe for modern remote education by combining mobile learning mode so as to improve the learning achievements as well as cultivate students' ability of independent learning, analysis and problem solving.
\end{abstract}

Keywords-M-learning mobile phone learning; online course; teaching reform

\section{INTRODUCTION}

Foreign researches on mobile learning have been conducted for four to five years. Besides, they are mostly in Europe, North America and other developed countries. The researches are mainly classified into two types: The first type is launched by online suppliers, who make full use of their experience in online e-teaching area so as to better put mobile learning to the market. They want to introduce mobile learning into campus for the purpose of improving the current education and management. At present, the researches on mobile learning are carried out not long ago. However, the development demonstrates quite a robust tendency. Therefore, more and more scholars, educators and professional trainers are devoting to the field. In addition, in the process, new technology and ideas are worth domestic scholars' learning.

In the undergraduate major of Computer Science and Technology in China Central Radio \& TV University, among various disciplines, one course called "Basis of Mutimedia Technology" is one selective subject, which mainly involves some professional foundamental knowledge and technology related to multi-media computer as well how to carry out research and utilization. Under the help of the theme project, the theme group introduces the new learning mode of "mobile learning" into the development and construction of online course and reforms practices, appraisal methods and other aspects so that it can be suitable for students' mobile learning.

\section{II .PATtern AND Principle OF OnLine Course Design}

Online course design adheres to the principle of conforming to the pattern of modern remote teaching so that different levels of students can understand teaching contents and obtain the knowledge they need through online learning. The course mainly adopts the teaching mode of "based on students' independent learning and supplemented by teachers' teaching”, provides corresponding learning guidance and various learning resources and cultivates vocational school students' independent learning ability.

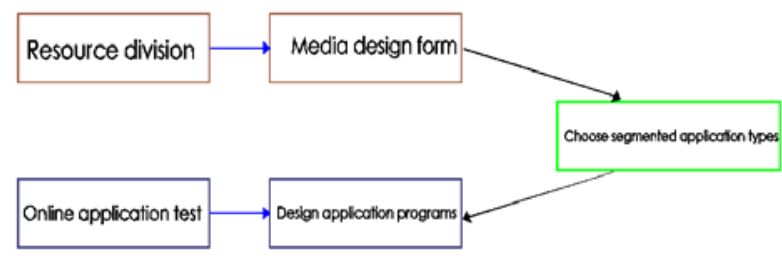

Figure 1. General Design Procedure

In Fig.1, we mainly carry out planning design of the online course from five aspects, i.e., resource division, design and planning of media types, selection of application types, design of application programs and launching onto the Internet.

\section{A. Contents design}

For the design of micro learning, it mainly includes three aspects, i.e., learning contents design, media design and interaction design. In terms of contents design, it refers to separating learning content, dividing it as one independent entity into small separated parts and connecting them with relevant knowledge connections. Through learning, students can gradually master the small independent parts. Finally, students can master all the knowledge by connecting all the 
parts. In terms of the manifestations of learning contents, they must be designed to be different for different individuals. Different learners have different learning methods. This feature should be demonstrated through the design of media forms. With the demonstration forms of media, learners can choose segmented application forms which are suitable for themselves independently. Finally, suitable and qualified segmented application programs can be formed to adapt to micro learning. After repetitive test and check as well as improvement, the most perfect software system is completed.

\section{B. Divide resources reasonably}

For micro learning, learners do not take the optimal learning attitude or focus their concentration in the whole process. As a result, it is very important to arrange learning reasonably according to students' own features. Only through distributing learning contents accurately can learners devote to learning more easily and quickly.

In order to form simple learning segmentations, first, we should clarify learning targets. Micro learning is one special learning mode. Only simple and independent learning methods can help learners with their learning better and more quickly. For micro learning, independent learning modules are required. Besides, "bonds" connecting the independent modules are also necessary. Only mutual connections can make learning contents more coherent as one complete knowledge frame. Finally, learners can finish their learning tasks. In addition, learning contents should be rich and able to attract learners' interest. Only after learners find interests can they transform such interest into learning motives. As a result, we should fully excavate learners' interest, hobbies as well as their working and learning habits so that we can divide learning contents reasonably.

\section{Manifestation forms of learning contents and corresponding methods}

In general, learning contents which are manifested with media adopt five forms, i.e., images, text, sound, video and flash. First of all, in terms of text, compared with other methods, it is the most frequently seen. It is dull and boring. It cannot well attract learners. Therefore, such a form is usually adopted in announcement, notice, explanation and so on. Second, in terms of images, compared with texts, images are more vivid. They can stimulate learners' interest at the first time and activate their learning motives. In addition, the form of combining images and texts can better attract learners' interest. Besides, learners are more wiling to accept and learn the contents. Third, in terms of sound, it is a special learning mode, which is mainly adopted in language teaching. Fourth, in terms of video, it can redemonstrate the scene authentically so that learners can put themselves on the scene personally and have a better understanding of the contents with both listening and seeing. Finally, in terms of flash, it is one vivid teaching mode, which can well demonstrate knowledge to learners. In general, animation is applied in experimental phenomena, data model and so on.
If we have an overview of all the mobile terminal browsers, we can find that all the audios and videos share certain similarities in terms of their formats. At the same time, due to the low efficiency of flash in videos in the past, new HTML5+CSS3 is designed to be applied gradually in the new Web to change the past status. So far, many terminals on the Internet begin to accept HTML5+CSS3 and support it. Therefore, the technology has become the major approach in flash, audios, videos and other media forms. At the meantime, learners can not only learn the knowledge but also download these contents on the Internet so that they can keep learning repetitively.

In course design, we stick to the following principles.

\section{Aim at cultivating applied talents}

The goal in higher vocational schools is to cultivate applied talents. In terms of content setting, it should correspond with the goal. In the process of content selection and practical teaching, we should base on theoretical knowledge, center around practical cases and aim at comprehensive application. In practical teaching, we should adopt case teaching. On the prerequisite of focusing on application, case teaching takes into consideration the development of applied technology and more accords with students' practical demands.

\section{E. Combination of theory and practice}

We should combine theories and practices and construct the teaching system of integrating "teaching, learning and doing”. We can start from six aspects, i.e., "basic concept”, "technological application", "operational skills", "knowledge expansion", "exercise explanation" and "training guidance". It both corresponds teaching contents with the requirements of the subject and stresses fundamental knowledge and practices. In addition, the method highlights practicality.

\section{F. Adopt the design idea of "segmentation"}

We conduct task "segmentation" design in terms of each chapter in "Basis of Multi-media Technology". Centering on the background of the teaching contents, we segment the contents into explicit, small, independent and intercorrelated parts. The divided knowledge modules should also have certain connection. Finally, learners can realize the learning objective. In addition, the contents in micro learning should be attractive so as stimulate learners' interest. Only through this can learners can have the interest and motive in learning. Therefore, it is of great importance to know learners' interest, hobbies and learning habits. Only after knowing this can we divide learning contents perfectly and ensure learners' learning quality.

\section{G. Combine teaching and self-learning; design multi-} layered learning-guiding processes

The teaching targets of the course are adult students. Their professional backgrounds and knowledge vary greatly with the students in normal colleges and universities. Therefore, we have taken these differences into consideration in teaching design and implementation. 
According to the characteristics of online teaching, we have established the teaching website as well as online courses suitable for students' independent learning. In students' selflearning process, rational and reasonable guidance is one critical process. For this reason, we have designed multilayered learning-guiding processes in the course. In the whole learning guidance, we mainly introduce the features of the course and knowledge system. In terms of chapter learning guidance, it is made up of background, teaching focus, requirement on ability and other parts. In this way, students can understand course contents and focus in an overall manner.

\section{THREE-DIMENSIONAL TEACHING RESOURCES}

In order to improve teaching effects, we have established three-dimensional, diverse and overall teaching resources for the course of "Basis of Multi-media Technology". Refer to Fig.2 for the structure of teaching resource.

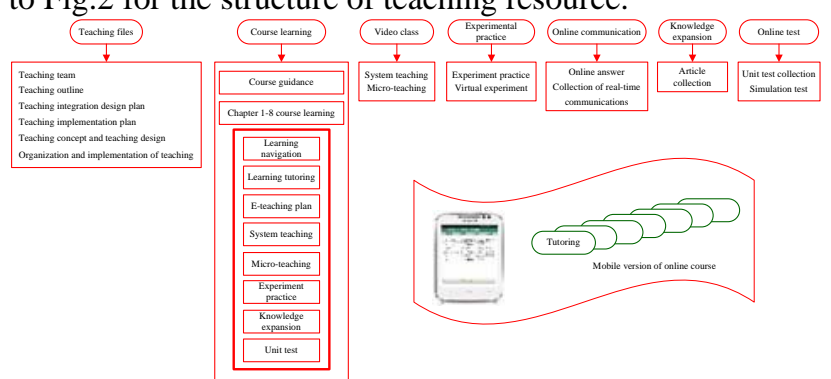

Figure 2. Structure of three-dimensional teaching resources in the course of "Basis of Multi-media Technology"

Many mobile learners are characterized by short learning time, complicated learning environment, intensive disturbances and so on. It also requires that the learning modules should be brief and highlight the focus. In addition, module design should be based on short-period learning task completion. We should also violate the design idea in teaching design model. The mobile learning time should be compacted into five minutes or more, less than 30 minutes. The whole PPT should provide various options for students, such as 5-minute class, 10 -minute class, 30-minute class and so on. However, in general, according to students' learning characteristics, such as inability to concentrate on learning, weak sustainable learning, little information absorption, complexity of learning environment and so on, 30 minutes is a little longer. It is not beneficial for students to concentrate on learning. Therefore, 5 minutes or 10 minutes is more suitable. In fact, every knowledge point is independent and complete. In other words, every knowledge module includes one or several relatively complete knowledge points. Within the independent five or ten minutes, learners can digest and comprehend the modulized learning contents. Among the modules, there are multiple connecting methods, such as summarization, simple hint and so on. With these methods, one complete and systematic knowledge system can be constructed for the dispersed knowledge.

In addition, there are also PPTs about theory and practice teaching, computer examination, evaluation systems, specific teaching websites, etc. Besides, the teaching website provides remote teaching, discussion, practice, examination evaluation, resource downloading and other teaching supporting methods.

In all, whether text materials or the construction of teaching resources, they all pursue for distinctiveness, innovation, advancement and demonstrativeness. Besides, they should be able to effectively improve teaching effects and quality.

\section{TEACHing Management Module for Mobile LEARNING}

Due to the rapid development of information technology, information handling in daily life also transforms from the domination of singular texts to the combination of texts, sound, graphics, images and other media information. As a result, "Basis of Multi-media Technology" starts from the perspective of application and elaborates on the basic concept of multi-media computer, operational skills and technological application. The course is featured with comprehensiveness and practicality. In addition, the course aims at mastering the basic theoretical knowledge of multimedia, basic applications and practical operations (Photoshop, Authorware, Premiere, etc.) so as to lay a sold foundation for later work or relevant course learning.

The mobile phone version of mobile learning should be simple and practical, including information, tutorship, score, attendance check, examination and so on. On the management platform, teachers can conduct student registration, score input, learning information management and course module arrangement. Besides, students can carry out score check and information feedback.

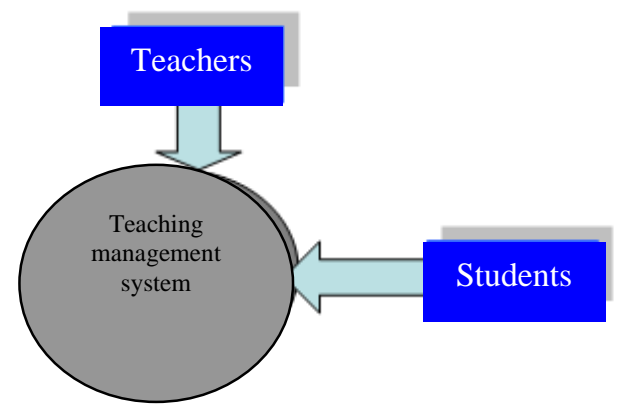

Figure 3. Teaching management system in mobile learning

The methods for evaluating learning score are as follows.

- Class note-taking: Learners should be required to take notes in class. After teaching two chapters, teachers should check the notes and give scores. There should be six checks in total. In every check, those who obtain full marks (100) will get five scores. Therefore, the scores of the six checks total to 30 scores.

After-class homework: There are six times of after-class homework in total. Learners who obtain full marks (100) will get five scores. Therefore, the scores of the six times of homework total up to 30 scores. The homework 
is assigned on course learning platform. Learners are required to complete the homework on line.

Experiment practices: Those who obtain full marks (100) will obtain five scores. Learners should complete experiment practices in virtual laboratories.

- Class attendance: There are 30 units in the course. Each unit occupies 0.5 scores in terms of class attendance. It totals up to 15 scores.

- Final examination: The students can look up reference books in the open examination. Those who obtain full marks (100) will obtain twenty scores.

\section{CONCLUSION}

From the above elaborations, we can see that multimedia is one important mobile tool in micro learning. Many referential materials and theoretical guidance cannot be separated from multi-media teaching. Through planning and designing micro learning with multi-media, we aim at enabling learners to better master knowledge. In the process of media design, what is the most important is that learners should master technology and media's operation as well as understand equipment and technology. Based on this, we can really put design into practice.

In the design, it adopts combined multi-media knowledge package in teaching, transmits learning materials and connects the materials. It is quite reasonable. Specifically speaking, the design combines and connects various media, such as images, sound, flash or videos to constitute the contents in the learning material package with the main line, i.e., texts. The design also carried out hypermedia learning through HTML media making software. The design highlights the focus, difficult points and important knowledge points with different character forms, such as different colors, sizes, bold characters and so on clearly and directly. In addition, with reasonable application of hyperlinks, it explains learning in details and displays the contents in the mobile learning package in the form of audios, images, videos, flash and so on.

\section{ACKNOWLEDGMENT}

This research is supported by the 12th five-year plan project in hunan province(No. XJK013BXX006) and
Education and Teaching Reform Project of Professional Colleges in Department of Education Hunan Province (ZJC2012029)

\section{REFERENCES}

[1] Lv Yao, A live experience on smartphone learning. Distance Education in China 22 (2010)14-14.

[2] Li Mizhen, Mobile learning and new product application summit forum. Distance Education in China (2013) 97-97.

[3] Lai Zuomei, Performance Comparison of Temporal-Frequency BlockMatching Motion Estimation Algorithm.Computer Engineering and Applications 42(2006)77-79.

[4] Li Zhiguo, An Jinwen, Global motion estimation algorithm based on phase correlation.Computer Measurement \& Control 16(2008)532534.

[5] Chen feng, Application research of digital image processing method for improving signal to noise ratio of seismic section image, Progress in Geophysics18(2003) 758-764.

[6] Fang Baolei, Li Mingzheng, Qiu Yu, Improvement on H.264 UMHexagonS-based motion estimation algorithm. Computer Applications and Software 30(2013)280-282.

[7] Wu Yifeng, Yu Liang, A header bits length estimation algorithm for H.264 based on spatio-termporal correlation. Modern Computer (2013)6-9.

[8] Huang Shuai, Song Guoxin, 2006, Hexagon-based Self-adaptive Search Algorithm Using Successive Elimination. Computer Engineering 32(2006) 212-214.

[9] Han Zhigeng, Wang Jian, Research and improvement of the marking block in the PMVFAST algorithm. Computer Engineering\&Science 28(2006) 70-72.

[10] Liu Changjin, Guo Li, Block matching criterion based on DCT coefficients distribution. Mini-Micro Systems 27(2006) 893-895.

[11] Wei Chang Wong, Chi Chiu Chan, Li Han Chen, Tao Li, Kok Xian Lee, Kam Chew Leong, Polyvinyl alcohol coated photonic crystal optical ber sensor for humidity measurement, Sensors and Actuators B: Chemical, 174 (2012), 563-569.

[12] A.M.S. Muniz, H. Liu, K.E. Lyons, R. Pahwa, W. Liu, F.F. Nobre, J. Nadal, Comparison among probabilistic neural network, support vector machine and logistic regression for evaluating the efect of subthalamic stimulation in Parkinson disease on ground reaction force during gait, Journal of Biomechanics, 43(4) (2010), 720-726.

[13] Nima Mohseni Kiasari, Saeid Soltanian, Bobak Gholamkhass, Peyman Servati, Room temperature ultra-sensitive resistive humidity sensor based on single zinc oxide nanowire, Sensors and Actuators A: Physical, 182 (2012), 101-105. 